\title{
AÇÕES PROMOVIDAS PELO MUNICÍPIO AOS MORADORES DE RUA DA CIDADE DE UBERLÂNDIA-MG NA PANDEMIA
}

\author{
Elaine Gomes do Amaral ${ }^{1}$ \\ Paulo Roberto Rodrigues Brandão Nogueira ${ }^{2}$ \\ Márcio de Freitas Santa Ana 3
}

RESUMO: Artigo trata das formas de interação entre a população em situação de rua no município de Uberlândia-MG e a atuação do Poder Público, no caso a prefeitura, em tempos de COVID-ı, com ações desenvolvidas em benefício dessas pessoas. OBJETIVO: Descrever as ações junto às pessoas em situação de rua devido à vulnerabilidade diante da Covid-I9 no município de Uberlândia entre março de 2020 e abril de 202r. Método: Busca na literatura utilizada foi à busca de publicações, Literatura Latino-Americana e do Caribe em Ciências da Saúde (LILACS) e Google Acadêmico. RESULTADOS: Prefeitura de Uberlândia intensificou o cuidado com as pessoas em situação de rua, adotando várias medidas de proteção voltadas a essa população com busca ativa diária realizando os encaminhamentos necessários para as pessoas com sintomas de COVID-i9. CONCLUSÕES: Poder público atuou de forma satisfatória no acompanhamento e no acolhimento destas pessoas moradores de rua.

Palavras-chave: Coronavírus. Pandemia. Pessoas em situação de rua. Saúde Pública.

\section{INTRODUÇÃO}

De acordo com a Política Nacional para a População em Situação de Rua (PNPR) Decreto no 7.053/2009 -, essa população pode ser caracterizada como "grupo populacional heterogêneo que possui em comum a pobreza extrema, os vínculos familiares interrompidos ou fragilizados e a inexistência de moradia convencional regular, e que utiliza os logradouros públicos e as áreas degradadas como espaço de moradia e de sustento, de forma temporária ou permanente, bem como as unidades de acolhimento para pernoite temporário ou como moradia provisória" (Brasil, 2009b).

\footnotetext{
I Graduação em Biologia - Mestre em Saúde Ambiental e Saúde do Trabalhador - Universidade Federal de Uberlândia elainegamaral@gmail.com

${ }^{2}$ Graduação em Biologia - Doutor em biotecnologia marinha pelo IEAPM/UFF- Instituto de Estudos do Mar Almirante Paulo Moreira/Marinha do Brasil- Arraial do Cabo-RJ. - Universidade Estácio de Sá - Campus Cabo Frio.Paulorrbn@hotmail.com

3 Metrado em Ciências e Tecnologias dos Materiais e graduação: Engenharia de Produção. E-mail: ciedistancia@gmail.com.
} 
Estudo realizado por Natalino (2016) estimava a existência de cerca de Ioo mil pessoas em situação de rua no Brasil, concentradas em municípios de grande porte (acima de roo mil habitantes). Em fevereiro de 2020, havia mais de 146 mil pessoas que se declararam nessa situação no Cadastro Único de programas sociais do governo federal (Brasil, 2020). Uma nova estimativa da população de rua indica, por sua vez, que, em março de 2020, tínhamos cerca de 220 mil pessoas em situação de rua (Natalino, 2020).

Há levantamentos municipais e uma pesquisa nacional, publicada em 2008, que demonstram não apenas o quantitativo da população de rua, mas também aspectos fundamentais de suas condições de vida. Entre 2007 e 2008, foi realizado o I Censo e Pesquisa Nacional sobre a População em Situação de Rua, englobando 7I cidades e identificando quase 32 mil pessoas acima de 18 anos. Foram entrevistadas pessoas em vias públicas, viadutos, galpões e outras estruturas precárias, além daqueles que se encontrava em albergues. São em maioria homens (82\%), negros (67\%), jovens (43,21\% dos homens e 52,23\% das mulheres até 35 anos), com baixa escolaridade ( $17,1 \%$ é analfabeto). Estão na rua ou em albergues há bastante tempo $(48,4 \%$ há mais de 2 anos), o que atribuem prioritariamente a problemas com álcool e/ou outras drogas (35,5\%), desemprego (29,8\%) e desavenças familiares (29,1\%). Seus vínculos familiares estão rompidos ou bastantes fragilizados (51,9\% têm parentes na cidade em que se encontra, mas $38 \%$ não mantêm contato).

A maior parte trabalha (70,9\% exercem alguma atividade remunerada e 58,9\% afirmam ter alguma profissão). Apresentam algum problema de saúde, em proporção acima da população geral de baixa renda (30\% têm algum problema de saúde) e $24,8 \%$ não tinham documentos (Sagi/MDS, 2009). Com efeito, esta pesquisa mostrava um cenário de população de maioria masculina, negra, com situação cristalizada de rua, com baixa escolaridade e alijada de amparo governamental básico. Por sua vez, também contribuiu para desfazer alguns mitos e preconceitos, mostrando que a situação de rua não necessariamente advém da migração e que este grupo é produtivo, ainda que atuando em atividades precárias.

A pandemia do novo coronavírus atinge as pessoas em situação de rua, que sobrevivem em precaríssimas condições de existência, contando com o Poder Público, estando na linha de frente da atuação, através do Sistema Único de Assistência Social (SUAS), com os Centros de Referência Especializados de Assistência Social (CREAS) e os Centros de Referência 
Especializados para População em Situação de Rua (Centros Pop); o Sistema Único de Saúde (SUS), comos Consultórios nas Ruas, e também há de considerar as ações caritativas de grupos religiosos e a atuaçãodas organizações não governamentais (ONGs) em seu cotidiano.

$\mathrm{Na}$ medida que a pandemia se dissemina, a OMS e o Ministério da Saúde do Brasil reforçam a necessidade do isolamento social com o uso de máscaras, lavagem das mãos e o uso de álcool em gel como medidas gerais para se evitar a propagação do vírus, ficando essa população a merce da propria sorte As ações tomadas por municípios e estados foram a adaptação de acolhimento já existentes ou criados temporariamente, destinados ao acolhimento da pessoa moradora de rua, com estratégias de infraestrutura como prevenção e conscientização. Houve articulação entre diferentes setores do govermo, com captação de espaços culturais, religiosos, educacionais para serem utilizados como estrutura de acolhimento.

A Secretaria Municipal de Desenvolvimento Social, Trabalho e Habitação (Sedesth) têm por finalidade planejar, coordenar, executar e aprimorar o Sistema Único de Assistência Social no Município de Uberlândia, em conformidade com a Política Nacional de Assistência Social, desenvolvendo um conjunto integrado de ações socioassistenciais de Proteção Social Básica e Especial, buscando a garantia de direitos e atendimento das necessidades sociais do público-alvo da assistência social, conseguindo repasses de recursos financeiros complementares à subvenção para aquisição de materiais e de ações necessárias durante o período pandêmico para os abrigos.

O monitoramento e avaliação destas instituições são realizados diariamente visando à prevenção de contágio dos funcionários e dos usuários em acolhimento, sendo repassadas orientações sobre o uso adequado dos equipamentos de proteção, normas de segurança e prevenção à Covid-ı, reforçando a importância de manter o distanciamento e o isolamento social.

Foram adaptados os CEAMI (Reabilitação para vida) onde atende dependência química, acompanhamento social, projetos de alfabetização de adultos, terapias ocupacionais, artesanatos, reuniões e acompanhamentos com as famílias, em conjunto com abrigo Instituição Cristã de Assistência Social (ICASU) e albergue Ramatis, utilizando recursos complementares para a aquisição de materiais e ações necessárias durante o período 
pandêmico. Para estes espaços, a Sedesth ainda doa itens como leite, bolachas, óleo de soja, bebida láctea, embutidos (mortadela) e kits de higiene pessoal.

Para evitar a disseminação do coronavírus, todos que apresentam sintomas e ou suspeita de contaminação são encaminhados para isolamento, sendo solicitada a testagem de Covid-ı, em parceria com a Secretaria Municipal de Saúde. Para este encaminhamento foi criado no CEAMI das Chácaras Panorama um espaço de quarentena para a permanência das pessoas encaminhadas. Todos os dias são elaborados um informativo referente às pessoas em situação de rua nas que se encontra em vias públicas e instituições de acolhimento com sintomas de Covid-ı9. Nestes casos, é realizado o encaminhamento das mesmas para a rede pública de saúde. Também são feitas orientações e inclusões de usuários no Cadastro Único e em programas e benefícios socioassistenciais e emergenciais públicos.

A prefeitura também dispõe de instituição de apoio como a da casa Santa Gemma que é uma entidade assistencial originada de iniciativa de membros da Igreja Católica Apostólica Romana, aberta a moradores e/ou pessoas em situação de rua que precisam de uma refeição, um banho ou abrigo de forma temporária ou permanente, com a capacidade de 17 internos, a casa não recebe ajuda de prefeitura ou órgão público, sobrevivendo de doações voluntárias, de empresas e de pessoas.

Com o isolamento e o esvaziamento das ruas essa população se viu prejudicada de onde tirar sua sobrevivência, surgindo a fome, a sede e ausência de locais para o banho e necessidades fisiológicas, surgindo assim a necessidade de atuação dos três albergues que atendem diariamente cerca de 120 pessoas. São oferecidos alimentação, banho e abrigo e as pessoas dormem por uma noite ou mais, estão localizados nos Bairros Roosevelt, Chácaras Panorama e Centro.

\section{OBJETIVO}

Descrever as ações junto às pessoas em situação de rua devido à vulnerabilidade diante da Covid-ı9 no município de Uberlândia entre março de 2020 a abril de 202I.

\section{MÉTODO}

Busca na literatura utilizada foi à busca de publicações, Literatura Latino-Americana e do Caribe em Ciências da Saúde (LILACS) e Google Acadêmico. Utilizaram-se os 
seguintes conceitos indexados em português, conforme os Descritores Utilizados em Ciências da Saúde (DeCS). Por se tratar de um estudo descritivo, de base meramente bibliográfica, não foi necessária a submissão para apreciação ética.

Levantamento das ações feitas no município de Uberlândia-MG no período de março de 2020 a abril de 202I.

\section{RESULTADOS}

Em pesquisas de 2014 e 2015, foram identificados em Uberlândia- MG 2.60o moradores de rua sendo atendidos pelo Centro Pop (Centro de Referência Especializado para População em Situação de Rua), sendo que destes, 1688 eram novos moradores de rua. Também foram atendidos população em situação de rua através de projeto desenvolvido pela equipe da Sedesth onde foram realizados 170.391 procedimentos junto a esta população, sendo acompanhada uma média de 106 pessoas diariamente.

Esse atendimento foi possível com a ampliação de i6o leitos nos quatro abrigos subvencionados pela gestão municipal, medidas feitas pela Secretaria Municipal de Desenvolvimento Social, Trabalho e Habitação (Sedesth), com a ajuda da empresa Smurfit Kappa que fez doação de 200 novas camas. Utilização de casas de atendimento os CEAMI espalhadas pela região com atendimento de cerca de mais de IIo pessoas. Além disso, as medidas de higiene foram intensificadas, com a disponibilização de álcool em gel nos locais, com equipes da prefeitura constantemente nos locais para prestar orientações sobre medidas preventivas.

\section{CONSIDERAÇÕES FINAIS}

Com o advento de Covid-ı, município intensificou o atendimento e ações para os moradores de rua. As medidas foram implantadas com base nas orientações do Núcleo Estratégico do Comitê Municipal de Enfrentamento à Covid-ı9, do Ministério da Cidadania e da Política Nacional para a População em Situação de Rua, além de outros instrumentos legais.

A pandemia de COVID-ig revela, as mazelas sociaisvividas no cotidiano, cobertas pelo mantoda invisibilidade. Suas necessidades passam a ser urgente, por possuírem muitos fatores 
preditivos a doença, em consequênciado seu caráter de fácil transmissibilidade, difícil controle e altaletalidade, necessitando de auxilio devido a esse cenário devastador, o contextodas pessoas que habitam as ruas, já que a maioria é de idosos e com comorbidades.

O isolamento social impôs novos desafios à toda população mundial, mas ainda maior para aqueles sem possibilidade deisolamento desprovidos de necessidades básicas, como a oferta de água e de alimentos.

Necessitando de efetivação de uma políticapública intersetorial que os alcancem, com medidas concretas eefetivas nesses dias ainda mais difíceis.Mediante o exposto, é possível compreender que os modosde viver e a cultura local da pessoa que mora na rua nos temposda COVID-I9 avivam ainda mais seus instintos de sobrevivênciae de preservação da vida, gritam pela fome e pela falta de água.Precisa-se pensar em outros modos de isolamento social para pessoas que vivem na rua. Representam, assim, um grandedesafio à saúde pública, invocando a capacidade de articulaçãoentre vários setores, como a saúde e a assistência social e a habitação, que, de forma conjunta e significativa, podem propormedidas que cooperem para minimizar o impacto da doença neste grupo populacional.

\section{REFERÊNCIAS}

BRASIL. Resolução I09, de II de novembro de 2009. Aprova a tipificação nacional de serviços socioassistenciais. p. $1-43,2009^{-\underline{a}}$

- Decreto no 7.053, de 23 de dezembro de 2009. Institui a Política Nacional para a População em Situação de Rua e seu Comitê Intersetorial de Acompanhamento e Monitoramento, e dá outras providências. Brasília, 23 dez. 2009 b.

CASA SANTA GEMMA. Disponível em:<www.casasantagemma.com.br >. Acesso em: 06/04/2021.

CEAMI. Disponível em: 〈http://www.ceamimissoes.com.br〉. Acesso em I6/o4/2013.

CORREIO DE UBERLÂNDIA. Abrigo para vítima de violência doméstica volta a funcionar em Uberlândia. Disponível em: http://www.correiodeuberlandia.com.br/cidadeeregiao/ abrigo-para-vitimas-de-violencia-domestica-volta-a-funcionar-em-uberlandia>. Acesso em i6/o4/2021. 
JORNAL PARANAÍBA. Centro Pop atende 700 pessoas que vivem nas ruas. Reportagem exibida em II/o8/20I. Disponível em:< https://www.youtube.com/watch?v=mszmGG72_xU>. Acesso em: 04/2021.

NATALINO, M. A. C. Estimativa da população em situação de rua no Brasil. IPEA, 2016. p. 36. (Texto para Discussão, n. 2246). . Estimativa da população em situação de rua no Brasil. 2020. (No prelo).

NATAliNO, M. A. C.; PINHEIRO, M. B. Proteção social aos mais vulneráveis em contexto de pandemia: algumas limitações práticas do auxílio emergencial e a adequação dos benefícios eventuais como instrumento complementar de política socioassistencial. IPEA: Disoc, 2020. (Nota Técnica, n. 67).

PREFEITURA MUNICIPAL DE UBERLÂNDIA. Secretaria cria comitê voltado para atendimento aos moradores de rua.Disponível em: 〈http://www.uberlandia.mg.gov.br/?pagina=agenciaNoticias\&id=4915> Acesso em I6/04/2021.

REDE GLOBO. Pessoas que vivem nas ruas têm perfil mapeado em Uberlândia. Disponível em: <http://gi.globo.com/minas-gerais/triangulo-mineiro/noticia/2013/ro/pessoas-quevivemnas- ruas tem perfil mapeado em-uberlandia.html>. Acesso em 04/04/2021. 